\title{
Knowledge of Whys and Hows of Healthy Aging of Women, Essential amongst Health Professionals
}

\author{
Chhabra, S.
}

\begin{abstract}
Background: Happenings in world have impacted elderly women by changes in health care systems, decline in fertility and mortality. There is an increase in life expectancy with significant changes in numbers and structure with rapid growth of the elderly population, needing attention of governments and policy planners. Health of elderly has remained neglected in health systems and in health professionals' education. The present article is an attempt to update and share the current context on the subject.
\end{abstract}

Disorders: Neurodegenerative disorders are common in elderly. Parkinsonism, difficulty in walking, talking, completing simple tasks etc. are most common, followed by Alzheimer's complex. In elderly women, both being overweight and underweight are seen more than in men in the same age group. Osteoporosis is common but is mostly identified following fractures. Pelvic floor dysfunction is a major health issue globally. Women with polycystic ovarian disease (PCOD) during peri-menopause often have hyperlipidaemia, hypertension, type 2 diabetes mellitus, impaired glucose tolerance, but these are under researched. Since women in this century are expected to live 30 to 40 years beyond menopause, risk of developing cancers is high but the most common cause of death above 60 is stroke.

Challenges: Elderly women lack quality life. Health systems and educational systems have gaps. Awareness of health professionals about health issues and health seeking problems is lacking.

Possibilities: Care of elderly women needs to be an important component of health professionals' education. Adequate training with vision beyond routine stream of individuals passing through examining rooms for prevention, therapy for elderly for best of health and quality life of women is essential.

Key Words: Elderly women

\section{Introduction}

There have been major occurrences in the world that have had impact on the elderly, be it better health care, the decline in fertility, the continuing decline in mortality etc. In addition, life expectancy has increased, which has resulted in significant changes in the number and structure of the elderly population. Their rapid growth is emerging as an area of concern for governments and policy planners (Ingle, 2008). The coming years will see an increasing number of elderly couples and widows, many of whom will have pressure to earn a livelihood due to lack of social security and insurance.

Department of Obstetrics Gynaecology

Mahatma Gandhi Institute of Medical Sciences, Sewagram, India

Email:chhabra_s@rediffmail.com
In addition to issues of sustainability, the process of aging is accompanied by increased vulnerability to illnesses. All these features of aging imply that the problems of the elderly need a special focus and approach. However health of the women beyond their reproductive age has largely remained a neglected issue in the health system and so in the health professionals' education as well.

The proportion of elderly persons in India was $6.5 \%$ in 1981 , grew to $6.8 \%$ in 1991 and $7.4 \%$ in 2001 (Laskar, 2011). According to the current estimates, life expectancy of Indian women is 67.57 years, and 65.46 years in men (NPHCE, 2009). Hence, there are more elderly women in India compared to men. Throughout her life, a woman plays different social roles; daughter, wife, mother, grandmother, care giver etc. These roles have an influence on her own health and wellbeing, quality of her life and that of her family. While older men have the privilege to retire from work, women are never 
relieved of social responsibilities. At the same time, the protective advantages of hormones are lost and women become more vulnerable to certain diseases than men, though research is revealing issues related to men also (Pommeruille et al., 2006). Thus in the present context it is essential that there is awareness in masses, especially health professionals regarding this issue.

\section{Disorders among elderly}

Old age, for most of the elderly implies many health related problems and this they perceive as a part of the normal process of ageing. Many of the problems where remedies are possible are accepted as part of the aging process and are not reported by women even during surveys. Parkinsonism is the most common neurodegenerative movement disorder, leading to difficulty in walking, talking, and completing simple tasks. Most individuals who develop Parkinson's disease are around 60 years or older. Lack of dopamine causes the motor symptoms of Parkinson's disease but, it is not clear why the dopamine-producing brain cells deteriorate. Dysfunctional cellular processes, inflammation, and stress, all can contribute to cell damage. Parkinsonism increases steeply with advancing age, but is consistently more often found in men, though drug related Parkinsonism is more common in women (Massano, 2012). In elderly women, significant reduction in bone mineral density (BMD) occurs with Parkinson's disease (PD), correlating with immobilization and with vitamin $D$ deficiency, increasing the risk of hip fractures (Sato et al., 2008).

Alzheimer's disease is another progressive brain disorder affecting elderly women. More often, this complex degenerative disorder results from the interaction of various risk factors. It is a long-standing disorder characterized by gradually progressing disturbances in the brain functions such as memory, decision-making, judgement and orientation to the physical surroundings (Nussbaum \& Ellis 2003).

The proportion of overweight as well as underweight women is more than that of men, i.e. women have poorer scores on both sides of the spectrum of nutrition than men (Laskar, 2011). Osteoporosis is common, but identified only at the time of fractures, which may occur even with minor injuries. Significant decrease in serum calcium has been reported in postmenopausal women, which can lead to osteoporosis. The prevalence of osteoporosis ranges from $52 \%$ in urban areas to $76 \%$ in rural areas in India (Chhiber, 2007).
Tinelli et al. (2010), report that though the aetiology of pelvic prolapse is poorly defined and multifactorial, risk factors associated with aging, such as biomechanical abnormalities in connective tissue composition, hormonal deficiency, and irregular tissue metabolism are non-modifiable and, therefore, pelvic prolapse is often seen in clinical practice. However, there is scope for its prevention from childbirth to menopause. In a study conducted by the author it was revealed that there has been no change in the rate of vaginal hysterectomy for genital prolapse over the years (Chhabra, 2013). Hysterectomy is a major surgical procedure with morbidity and mortality, thus in elderly, complete evaluation is essential and possible management options need to be discussed before surgery. According to a study by Olsen et al. (1997), pelvic floor dysfunction is a major health issue for older women, with around $11 \%$ having a lifetime risk of undergoing at least a single operation for pelvic organ prolapse and urinary incontinence, as well as a higher proportion at risk of repeat operations.

Women who have polycystic ovarian disease (PCOD) during peri-menopause often have hyperlipidaemia, hypertension and type 2 diabetes mellitus, or impaired glucose tolerance, similar to the features of the socalled "metabolic syndrome" or "syndrome X", which could lead to further sequelae later in life. Women with such conditions have seven times the risk of myocardial infarction and ischaemic heart disease (IHD) compared to women with no PCOD in the past (Adams, 1998). Adams (1998), reports that of women undergoing coronary angiography for IHD before the age of 60 years, $46 \%$ had $\mathrm{PCO}$ on ultrasound and the degree of coronary narrowing was greater in these women than in the remaining 54\%. Patient education and attention to diabetes, cardiovascular risk and obesity can help in women with PCOD during peri-menopause (Cipkala-Gaffiin, 2009).

It is believed that women have $23 \%$ probability of developing a cancer by the age of 79 years and $39 \%$ probability of death. The age at which natural menopause occurs is between 45 and 55 years for women worldwide (Dutta, 2014). Since women in this century are expected to live 30 to 40 years after the onset of menopause, the risk of developing a cancer is so much that nearly half of all women are likely to develop or, face it leading to an alarming, numbers of gynaecological cancers (Gyn. Ca.), a major cause of death in the elderly female population.

Gyn. Ca. deaths are the fourth leading cause of death in women. In western countries ovarian, 
endometrial and cervical cancer occur in the same order, while cervical cancer is the most common in developing countries, including India. In a study in Eastern Maharashtra, India, cervical cancer constituted around $29 \%$ of cancers in women, similar to reports by Arbyn et al. (2008): $76 \%$ of gynaecological cancers were cervical cancer (Chhabra, 2010). Cervical cancer, most often develops in women beyond the age of 50 because of various reasons, including the health consequences of living conditions, poverty, poor nutrition and frequent births. India accounts for $20-30 \%$ of the global burden of cervical cancer. In the author's study, there was an increasing trend among women older than 65 years, from $4.91 \%$ earlier to $16.5 \%$ in present times, possibly relating to the increasing life span. Compliance to therapy is less than one third in this part of word. Vulval cancers occur mostly in elderly and are more common in the western world (Chhabra 2013). Breast cancer and ovarian cancers are also leading cancers in elderly women.

Drug-related problems are common in the elderly and include drug ineffectiveness, adverse drug effects, over-dosage, underdosage, and drug interactions. Adverse effects are thought to be preventable in almost $90 \%$ of cases in the elderly, compared with only $24 \%$ in younger patients (Ruscin et al., 2014). While illicit drug users aged 50+ are a small group compared to illicit drug users of a younger age, illicit drug use also occurs in later life. The most commonly used illicit drug among older adults is marijuana; it is used by $3.9 \%$ of adults aged $50-64$ and $0.7 \%$ of adults 60 and older (Blazer \& Wu, 2014).

\section{Mortality}

The most common cause of death among women above the age of 60 years is stroke, leading to $21.7 \%$ of deaths, closely followed by ischemic heart disease (IHD) which leads to $19.8 \%$ of deaths. Chronic obstructive pulmonary disease (COPD) has been incriminated in $11 \%$ of deaths. Hypertensive heart disease and lower respiratory tract infections contribute to $3.7 \%$ and $3.4 \%$ of deaths, respectively, $3.2 \%$ of deaths have been attributed to diabetes, while cancers of different sites cause $6.6 \%$ of deaths (WHO, 2009).

\section{Challenges}

Whether or not there should be a fixed age group to define the elderly is often subject to debate, though it has been common practice to define old age in terms of the beginning of the sixties in the life span, characterised by retirement from work and certain other social responsibilities. Old age can be broadly characterised by time-altered changes in an individual's biological, psychological and health related capabilities and its implications for consequent changes in the individual's role in the economy and society. There are a vast number of issues that call for an attentive focus on the elderly, specially vulnerability of females (Irudaya, 1995).

Life expectancy of women is increasing but they may be disabled prior to death more often compared to male counterparts because of inherent issues. Due to longer life span of women and general societal norms of marrying men older than themselves, the increasing proportion of widowhood will also be a major concern (Dutta, 2012).

A multicentric study conducted by the Ministry of Health and Family Welfare (MOHFW), India in collaboration with the World Health Organization (WHO) revealed that $69.5 \%$ of women were living with a spouse or family. The proportion of elderly women living alone was more $(7.1 \%)$ compared to men $(4.5 \%)$. Only $24 \%$ of elderly women were economically active as against $44 \%$ men. Dependency ratio for the old has been rising from 105 per 1,000 in 1961 to 118 per 1000 in 1991 and 131 per 1,000 in 2001 . It is projected to be 161 by 2021 , (Laskar, 2011). Low literacy is also a problem among women in this age group which leads to less occupational opportunities and less economic security (Laskar 2011).

The traditional role that women play as the primary care givers, coupled with the lower status they enjoy, leaves them with limited access to financial resources for themselves as they become more dependent. One of the approaches towards studying the well-being of the elderly has been to study their "competence" in daily living, "functional competence" based approaches, assessment of their ability to manage the tasks of daily living, without dependence on others.

The health-related quality of life of the elderly, especially women from rural areas, is considerably lower in India compared to other countries.

A survey in Kerala (Rajan et al. 1999) on the health of the elderly revealed that women are poorer and suffer more morbidity than men in old age, although their death rates are lower. Among these, cough, poor eyesight, anaemia and dental problems were found to dominate. The study did not find striking differences between men and women in terms of health status and health seeking behaviour but elderly 
women's health problems were more often ignored because their families had no time to take them to the doctor or provide regular treatment which at times was unaffordable for many. Clearly the economic compulsions or ignorance of their condition force many of them to remain silent. When asked why they did not take treatment for something which was treatable and curable, the responses were 'it is God's wish', 'just because I am a woman nobody cares for me, and my husband is used to me looking after him and caring for him', poverty and economic status (Table 1). It is essential that the health professionals are aware of issues related to health of elderly and their problems in health seeking. The World assembly conference in Vienna in 1982, where countries adopted the United Nations International Plan of Action on Ageing, recognised the aged as a social category and 1999 was named the International Year of Older Persons. Quantitative as well as qualitative analysis revealed that women may be more vulnerable than men due to reasons such as lack of productive employment and income, widowhood and low education, all of which make them dependent on others and also less empowered, thereby unable to voice their needs and problems (Ingle, 2008). Aging ushers in biomedical changes that influence the effects of alcohol and drugs on the body. Alcohol abuse accelerates the normal decline in physiological functioning that occurs with age (Gambert \& Katsoyannis, 1995). In addition, alcohol may elevate the already high risk for injury, illness, and socioeconomic decline (Tarter, 1995).

Table 1: Lives of Elderly > 60 \& Issues - Status (Rajan et al., 1999)

\begin{tabular}{|c|c|c|c|}
\hline Item & Findings & Male & Female \\
\hline \multirow{5}{*}{ Source of livelihood } & Living on own income & 54.3 & 19.8 \\
\hline & Receiving support from NGOs/Govt & 1.0 & 1.3 \\
\hline & Supported by family & 42.3 & 76.8 \\
\hline & Destitute & 0.5 & 0.8 \\
\hline & Other & 1.8 & 1.1 \\
\hline \multirow{6}{*}{ Physical well being } & Indicator of physical well being & & \\
\hline & Fit, no major health problem & 65.1 & 64.1 \\
\hline & $\begin{array}{l}\text { No chronic problems, but assistance } \\
\text { needed }\end{array}$ & 4.6 & 5.5 \\
\hline & $\begin{array}{l}\text { Restricted activity with one or more } \\
\text { chronic problems }\end{array}$ & 6.5 & 6.6 \\
\hline & III, but not bed-ridden & 20.5 & 21.2 \\
\hline & Bed-ridden & 3.3 & 2.6 \\
\hline \multirow{7}{*}{ Nature of ailments } & Cough & 22.7 & 18.0 \\
\hline & Joint pains & 25.0 & 32.1 \\
\hline & Blood pressure & 6.5 & 7.8 \\
\hline & Heart disease & 2.6 & 3.3 \\
\hline & Diabetes & 4.8 & 1.5 \\
\hline & Cataract/loss of vision & 9.8 & 14.4 \\
\hline & Others & 27.2 & 21.6 \\
\hline \multirow{5}{*}{ Kind of medical care } & No care & 19.7 & 20.0 \\
\hline & Allopathy & 54.3 & 52.9 \\
\hline & Indigenous doctors & 13.3 & 14.0 \\
\hline & Paramedical care & 2.3 & 1.2 \\
\hline & Home remedies & 9.2 & 8.9 \\
\hline \multirow{6}{*}{ Health system } & $\begin{array}{l}\text { Indigenous practitioner/faith } \\
\text { health/religious person }\end{array}$ & 11.5 & 11.4 \\
\hline & $\mathrm{PHC} / \mathrm{CHC} /$ Sub-centre & 4.7 & 5.2 \\
\hline & Government hospital & 32.4 & 31.2 \\
\hline & Private hospital/nursing home & 10.0 & 10.4 \\
\hline & Private doctor-qualified & 30.1 & 31.2 \\
\hline & Private doctor-unqualified & 4.8 & 4.0 \\
\hline
\end{tabular}




\section{Possibilities}

Geriatric care needs to be an important component of medical and paramedical education. Health workers at primary level should also be equipped with knowledge and skills to address the problems of this special group.

Special provision for providing health care for the elderly in the primary health care system is a recent phenomenon. Programmes must be based on prioritising and targeting. A mixture of interventions would go a long way in helping the elderly. The potential to delay onset of problems for healthy aging can improve course of many chronic conditions. There is a scope for prevention in almost all the disorders which the elderly are likely to develop. In elderly patients, prescribers should always consider the possibility that a new symptom or sign is due to drug therapy and because the elderly often take many drugs, they are particularly vulnerable to drug interactions (Ruscin et al., 2014).

\section{General condition}

Health professionals need to provide appropriate health education to elderly patients. In order to keep memory intact, it is essential to try to remain mentally active. Healthy diet and physical activity are essential. Eye and ear care is imperative for remaining mentally active. Teeth become soft. Therefore it is essential to advise on regular brushing, use of gentle moisturizer, flossing and regular check-ups. Precautions about food items are essential depending on the condition of teeth. Weight must remain under control through physical activity and healthy diet, as being overweight or underweight can create problems. Bones, joints and muscles are affected with advancing age; bones tend to shrink in size \& density. Therefore it is essential to take adequate calcium and vitamin. D, and keep joints mobile. Management of stress by maintaining a positive attitude and avoiding substance abuse can go a long way in remaining healthy.

A healthy diet and active life can help to maintain a healthy digestive system. The urinary system too is affected as age, advances. In order to maintain bladder control, it is essential to engage in regular exercise, and schedule regular check-ups. Women must share their needs and concerns about their sexuality with their partner. In order to maintain healthy cardiovascular and respiratory systems, it is essential to have regular exercise, a healthy diet, avoid smoking, manage stress, avoid substance abuse and seek timely therapy, if the need be.
A balanced low fat diet that includes enough fruits with antioxidants is beneficial in improving general health. These measures may prevent the occurrence of common disorders or reduce the severity of the symptoms in Alzheimer's and Parkinsonism (Kedar, 2013). There is no simple way to make women aware of the importance of timely healthcare. In addition to health disorders, the treatment provided for such can also affect their health, therefore physicians need to take the time to provide adequate counselling. It is a difficult task to persuade women to use these services but it is often more difficult to, convince them to undergo a complete examination, especially a vaginal examination, especially in countries in South East Asia.

\section{Concluding comments}

Physicians and other health professionals must have adequate training and while working should expand their vision beyond the routine treatment of the stream of individual patients passing through their examining rooms, to a concern for the health needs of the larger community, including the health of women, in order to create a society free of disease with improved quality of life.

\section{References}

Adams, J., Polson, D.W. \& Franks, S. (1998) A Guide to Clinical Management Prevalence of polycystic ovaries in women with anovulation, Journal of Clinical Endocrinology \& Metabolism, 83, pp. 2694-2698.

Momber, L.T.M. \& Schoemaker, J. (2000) Women with polycystic ovary syndrome gain regular menstrual cycles with ageing, Human Reproduction, 8, pp. 379-384.

Arbyn (2008) Automation-assisted and liquid- based cytology for cervical cancer screening [Online] Available at http://www.health.gov.au/internet/ msac/publishing.nsf/Content/BAE45713D7DOFD EBCA257817001CB46D/\$File/1122_MSAC_Ass essment_Report.pdf.

Chhabra, S., Bhavani, M., Mahajan, N. \& Bawaskar, R. (2010) Cervical cancer in Indian rural women: trends over two decades, Journal of Obstetrics and Gynaecology, 30, 7, pp. 725-728.

Chhabra, S., Ramteke, M., Mehta, S., Bhole, N. \& Yadav, Y. (2013) Trends in Hysterectomy for Genital Prolapse: Rural Experience, Clinical Medicine Insights, Reproductive Health, 7, pp. 1116.

Chhiber, G., Roy, R., Euice, M. \& Srivastava, M. (2007) Prevalence of osteoporosis in elderly women living in Delhi and Haryana, Indian Journal of Endocrinology \& Metabolism, 11, pp.11-14. 
Chhabra S., Bhavani, M. \& Deshpande, A. (2013) Trends of Vulvar Cancer, Journal of Obstetrics and Gynaecology, 34, 2, pp. 165-168.

Cipkala-Gaffiin, J.A. (2009) An Evaluation of Psychosocial and Socio-demographic Factors Associated with Metabolic Syndrome and Cardiovascular Risk in Polycystic Ovary Syndrome Cases and Controls [Online] Doctoral Dissertation, University of Pittsburgh, Available at: http://udini.proquest.com/view/an-evaluation-ofpsychological-and-pqid:1885031951/.

Dutta, R., Dcruze, L., Anuradha, R. \& Rao, S. (2012) A Population Based Study on the Menopausal Symptoms in a Rural Area, India Journal of Clinical and Diagnostic Research, 4, pp. 597601.

Gambert, S.R. \& Katsoyannis, K.K. (1995) Alcoholrelated medical disorders of older heavy drinkers, In: Beresford. T.P. \& Gomberg E.L. (Eds.) Alcohol and Aging, Oxford: Oxford University Press, pp.70-81.

Gupta, I., Dasgupta, P., Sawhney, M., Health of the elderly in India Some Aspects of Vulnerability [Online] Available at: http://www.silverinnings. in/docs/Finance/InsuranceHealth\%20Insurance\% 20 for\%20Elderly\%20in\%20India.pdf.

Ingle, G.K. \& Nath, A. (2008) Geriatric Health in India: Concerns and Solutions, Indian Journal of Community Medicine, 33, 4, pp. 214-218.

Irudaya, R.S. \& Misra U.S. (1995). Defining Old Age: An Indian Assessment, Journal of United Nations Institute on Aging, Malta, 5, 4, pp. 31-35.

Kedar, N.P. (2003) Can we prevent Parkinson's and Alzheimer's disease? Journal of Postgraduate Medicine, 49, 3, pp.236-245.

Laskar, V.A. (2011) Women's health: Beyond reproductive years, Indian Journal of Public Health, 55, pp.247-251.

Massano, J. \& Bhatia, K.P. (2012) Clinical Approach to Parkinson's disease: Features, Diagnosis, and Principles of Management, Cold Spring Harbour Perspectives in Medicine, 2, p. 6.
National Programme for the Health Care Of Elderly (2009) An Approach towards Active and Healthy Aging, Delhi: Directorate General Health Services, Ministry Of Health and Family Welfare, Government Of India.

Nussbaum, R.L. \& Ellis, C.E. (2003) Alzheimer's disease and Parkinson's disease, New England Journal of Medicine, 348, 14, pp. 1356-1364.

Olsen, A.I., Smith, V.J., Bergstrom, J.O., Colling, J.C. \& Clark, A.L. (1997) Epidemiology of surgically managed pelvic organ prolapse and urinary incontinence, Obstetrics \& Gynaecology. 89, 4, pp. 501-506.

Pommerville, P.J. \& Zakus, P. (2006) Andropause: knowledge and awareness among primary care physicians in Victoria, BC, Canada, Aging male, 9, 4, pp. 215-220.

Ruscin, J.M., \& Linnebur, A.S. (2014) Drug-related problems in the elderly, [Online] Available from; http://www.merckmanuals.com/professional/ geriatrics/drug-therapy-in-the-elderly/drugrelated-problems-in-the-elderly.

Sato, Y., Honda, Y., \& Kaji, M. (2008) Amelioration of Osteoporosis by menatetrenone in elderly female Parkinson's disease patients with vitamin D deficiency, Bone, 43, 1, pp. 217.

Tarter, R.E., Beresford, T.P. \& Gomberg, E. (1995) (Eds.) Alcohol and Aging, New York: Oxford University Press.

Tinelli, A., Malvasi, A. \& Rahimi, S. (2010) Agerelated pelvic floor modifications and prolapse risk factors in postmenopausal women, Menopause, 17,1, pp. 204-212.

WHO (2009) Women and Health in India: Today's Evidence Tomorrow's Agenda in Older Women. Ch.6. WHO Report, pp. 59-67.

Wu, L.T. \& Blazer, D.G. (2014) Substance use disorders and psychiatric comorbidity in mid and later life: a review, International Journal of Epidemiology, 43, 2, pp. 304-317. 